\title{
Influence of practitioners' characteristics on risk assessment in Green Building projects in emerging economies: a case of Vietnam
}

\author{
Hung Duy Nguyen \\ Department of Management and Engineering, University of Padova, Vicenza, Italy \\ Quang Nhat Huu Do \\ GREENVIET Green Building Consultancy Company, \\ Ho Chi Minh City, Vietnam, and \\ Laura Macchion \\ Department of Management and Engineering, University of Padova, Vicenza, Italy
}

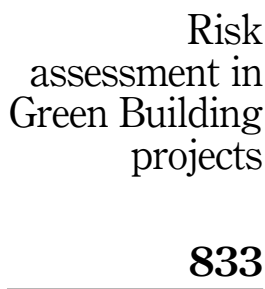

Received 23 May 2021 Revised 21 August 2021 Accepted 14 September 2021

\begin{abstract}
Purpose - Risks are considered a significant obstacle to Green Building (GB) development and have recently received significant attention from both construction practitioners and academics. This study aimed to identify critical GB risks and explore the relationship between participants' characteristics and risk assessment.

Design/methodology/approach - Firstly, a list of GB risks was developed based on a comprehensive literature review and interviewing GB experts. After that, a survey of 207 construction professionals was then conducted to validate these GB risk factors. Finally, this research adopted the ANOVA test and hierarchical regression analysis to examine the relationship between participants' characteristics and risk assessment.

Findings - The results provided a list of GB risks classified and evaluated according to the GB project life cycle and, thus, may serve as a helpful reference for GB practitioners. Notably, the ANOVA analysis revealed that risk assessment negatively correlates with participants' GB experience, while their industry experience does not affect risk assessment. Furthermore, the hierarchical regression analysis proved that participant roles do not moderate the association between risk assessment and GB experience.

Originality/value - This study contributed to GB literature by implementing empirical research on GB risks in a developing country. The results implied the essential role of professionals with rich GB experience in risk management in GB projects. Furthermore, this research could help construction practitioners understand GB risks adequately and thereby have better risk-management strategies for future GB projects.
\end{abstract}

Keywords Risk, Green buildings, Experience, Project roles, Personal characteristics, Sustainable construction Paper type Research paper

\section{Introduction}

The construction industry plays an essential role in the development of any country. However, construction activities also significantly contribute to environmental pollution and are among the main reasons for global climate change (Kientzel and Kok, 2011). In this context, Green Buildings (GB), derived from the green movement around the 1970-1980s, have arisen as resolutions for the construction industry to mitigate the negative influence on

(C) Hung Duy Nguyen, Quang Nhat Huu Do and Laura Macchion. Published by Emerald Publishing Limited. This article is published under the Creative Commons Attribution (CC BY 4.0) licence. Anyone may reproduce, distribute, translate and create derivative works of this article (for both commercial and non-commercial purposes), subject to full attribution to the original publication and authors. The full terms of this licence may be seen at http://creativecommons.org/licences/by/4.0/legalcode

The research is funded by the Fondazione Cassa di Risparmio di Padova e Rovigo.

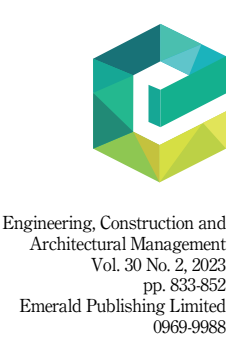

DOI 10.1108/ECAM-05-2021-0436 
ECAM

30,2

\section{4}

the environment but still meet the required functions of a building (Retzlaff, 2010). The difference between GBs and conventional buildings lies in the emphasis on social and environmental aspects (Ahmad et al., 2019).

Recently, there has been a substantial increase in the number of GBs all over the world. However, the GB development still confronts various barriers such as economic feasibility, awareness, support from stakeholders, legislation and risks (Gan et al., 2015). Among these, numerous risks in the implementation of GB projects have become a considerable obstacle and, in recent years, have received growing attention from both construction practitioners and researchers (Ahmad et al., 2019).

"No construction project is risk-free. Risk can be managed, minimized, shared, transferred, or accepted. It cannot be ignored" (Latham, 1994). Indeed, construction projects frequently face various problems, such as financial issues, quality issues and bad weather. Therefore, many construction projects suffer from significant losses due to poor risk management (Li et al, 2015). According to previous studies, risks should be managed effectively to succeed in construction projects (Chapman and Ward, 2004; Du et al., 2016). In particular, risk assessment (RA), which is a crucial step in the risk management (RM) process, should be implemented appropriately to control uncertainty situations (Islam et al., 2017).

According to previous studies, GB projects are riskier than conventional projects due to the use of high technology, innovative materials and novel construction procedures (Hwang, 2017a, b). This indicates that RM is even more crucial for GB projects compared to conventional projects. However, though the construction industry has studied RM in construction projects over the past decades, the research related to risks in implementing GB projects is still nascent. This phenomenon is understandable since risks in GB projects are fundamentally different from conventional projects, and the GB risk topic has just recently emerged. This issue could limit the understanding of how risks influence GB projects' implementation and thereby hinder GB development.

Recently, there has been growing concern in examining risks in implementing GB projects. Nevertheless, studies in this field are still limited. Notably, most previous studies were conducted in several developed economies, including Singapore, Australia, The US and China. Very few studies were implemented in emerging economies. Unlike in developed countries, GBs are still a new kind of building in most developing countries, such as Vietnam (Nguyen et al, 2017). This indicates that GB risks in developing countries are even more critical compared to developed countries. To date, very little is known about GB risks in emerging economies. This suggests the need to explore risks in the implementation of GB projects in developing countries.

To address this problem, the authors attempted to investigate risks in GB projects in Vietnam. The reason to choose Vietnam is that Vietnam is a typical emerging economy in Asia. Also, GBs had a notable improvement in Vietnam, and the number of GBs has been increasing recently (Analytics, 2018). Notably, previous research also indicated that risks in implementing GB projects are a significant obstacle to GB development in Vietnam (Nguyen et al.,2017). Thus, this study could fill the literature gap by studying GB risks in a developing country and also supports the development of GBs in Vietnam. In the first step, this research aims to identify a comprehensive list of GB risk factors and then categorize them according to three main phases in the GB project life cycle. Next, this study evaluated GB risks to determine the most critical risks and explored the relationship between RA and participants' characteristics.

\section{Literature review}

This section presents a review of GB risk studies in the current literature. This is the fundamental step to identify the preliminary list of GB risk factors. Also, we proposed 
several hypotheses that need to be tested by empirical research based on the literature review.

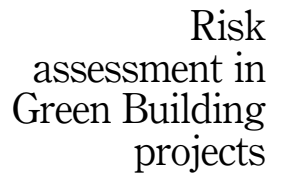

2.1 Background of GB risk research

A growing body of literature has investigated GB risks in recent years, as shown by the number of such studies increasing over the years (Ahmad et al., 2019).

For example, Hwang et al. (2017a) investigated risk factors in green residential building projects in Singapore. This research indicated that the most crucial risks in residential GB projects are "complex procedure to obtain approval," "overlooked high initial cost," "unclear requirements of owners," "employment constraint" and "lack of availability of green material and equipment." Likewise, other researchers in Singapore attempted to pinpoint and assess risks associated with commercial GB projects (Hwang et al., 2017b). This research revealed that "inflation," "currency and interest rate volatility worsened by the import of green materials," "durability of green materials," "damages caused by human error" and "shortage of green materials" are the top five critical risks. Both of the studies also attempted to compare risk levels between GB projects and traditional projects. The results showed that GB projects are riskier than traditional projects because of adopting high technology and innovative material to achieve sustainability objectives.

In China, another research investigated risks in GB projects based on sustainability aspects (Tao and Xiang-Yuan, 2018). The study revealed that "lack of experienced managers in the operation phase" and "the public's satisfaction with the project is meager" are the most critical risks. In the same way, Qin et al. (2016) attempted to evaluate risks throughout the life cycle of GB projects in China and rank the critical level based on the likelihood occur and impact level. The research also revealed the differences in stakeholders' risk preferences. Thus, this research contributed the necessary insight for stakeholders to manage risks according to specific roles.

In Kuwait, another study attempted to explore risks associated with sustainable construction (Ismael and Shealy, 2018). The result determined that the most critical risks in the Kuwait context are the lack of experience about GBs of designers and contractors. Besides, this research also revealed some other severe risk factors such as "high initial cost for material" and "the overall cost of projects." Notably, Rafindadi et al. (2014) endeavored to identify risks in GB projects based on stakeholders' views. Interestingly, the result indicated no significant discrepancy among stakeholders' perceptions about risks in sustainable projects. This somewhat conflicts with several other researchers who consider that RA is subjective and depends on stakeholders' characteristics (Qin et al., 2016). However, both these studies had the same limitation in that their sample sizes are small, which could lead to bias test results. Hence their findings should be assessed and generalized conservatively.

Based on reviewing the literature, a list of GB risks was created to serve as a starting point to obtain experienced professionals' input to identify GB risks in Vietnam.

\subsection{Research hypotheses}

The literature review results indicated a lack of research investigated the relationship between RA and practitioners' characteristics in GB projects. Therefore, this research aimed to explore how practitioners' characteristics influence the RA process. This may help stakeholders have more insights into GB risks and provide a valuable reference for the RM process in GB projects.

2.2.1 Potential effect of participants' experience on $R A$. As we know, the construction industry is a robust experience-oriented industry because of the uncertainties and complicated nature of construction projects. Indeed, practitioners regularly learn from their previous experience to make decisions and dealing with various assignments such as 
ECAM

30,2

836

estimating costs, making plans and solving onsite problems (Alhumaidi, 2014). Consequently, construction practitioners could gain multiple skills and knowledge in handling different work requirements.

Likewise, previous studies supposed that risk assessment and management in the construction industry depend mainly on practitioners' experience, knowledge and intuition (Patterson and Neailey, 2002; Raz and Michael, 2001). According to these studies, the two primary tools for the RA process are experience and individual judgment. Previous studies also revealed that sophisticated tools are almost not used extensively for the RA process in construction industries (Wood and Ellis, 2003). This phenomenon implies that practitioners' experience plays a crucial role in the RM process in construction projects. Therefore, experienced practitioners might assess risks more correctly compared to those inexperienced (Xia et al., 2018). One plausible hypothesis is that experienced practitioners are aware of risks better and, thus, have a more careful evaluation than those with less experience. This might hint that practitioners' experience negatively correlates with evaluating risk factors.

Because GB risks differ significantly from regular risks (Hwang et al., 2017b), this study considered two types of experience: GB-related experience and industry experience. Industry experience is the general experience that practitioners could gain by working in the construction industry. In contrast, practitioners could only achieve GB experience once participating directly in GB projects. Therefore, investigate the effect of each type of experience on RA separately is needed and an exciting direction.

In line with the above discussion, this research proposed two hypotheses:

H1. Practitioners' GB experience is negatively associated with RA.

H2. Practitioners' industry experience is negatively associated with RA.

2.2.2 Potential moderating effect of practitioners' roles. Construction projects frequently require numerous stakeholders with distinct roles and duties, such as owners, design consultants, contractors and project managers. Therefore, stakeholder management is critical in any construction project, especially in complex projects (PMI, 2017). Moreover, participants' views on risks regularly change significantly depending on project roles (Xia et al., 2018). Thus construction practitioners may have different perspectives about GB risks depend on their particular role in GB projects (Qin et al., 2016). This phenomenon suggested the possible moderating effect of practitioners' roles in the association between practitioners' experience and RA. Therefore, this study hypothesized:

H3. Practitioners' roles moderate the relation between GB experience (GBEx) and RA.

H4. Practitioners' roles moderate the relation between industry experience (Ex) and RA.

In summary, we formulated two sets of hypotheses. The first set $(\mathrm{H} 1, \mathrm{H} 2)$ aimed to test the relationship between RA and participants' experience (GB experience and industry experience). In contrast, the second one (H3, H4) intended to examine the moderating effect of participants' roles in the association between participants' experience and RA. The theoretical framework of this research is illustrated in Figure 1.

\section{Research methods}

The research methodology in this study comprisedthe following steps: (1) Identify the risk factors in GB projects based on review literature and interview experts; (2) Design the questionnaire survey to investigate the influence of risk factors in GB projects; (3) Collect data from experienced practitioners; (4) Implement descriptive analysis to explore the collected data; (5) Conduct hypotheses test; (6) Discuss research findings. The overview of the research methods is shown in Figure 2. 

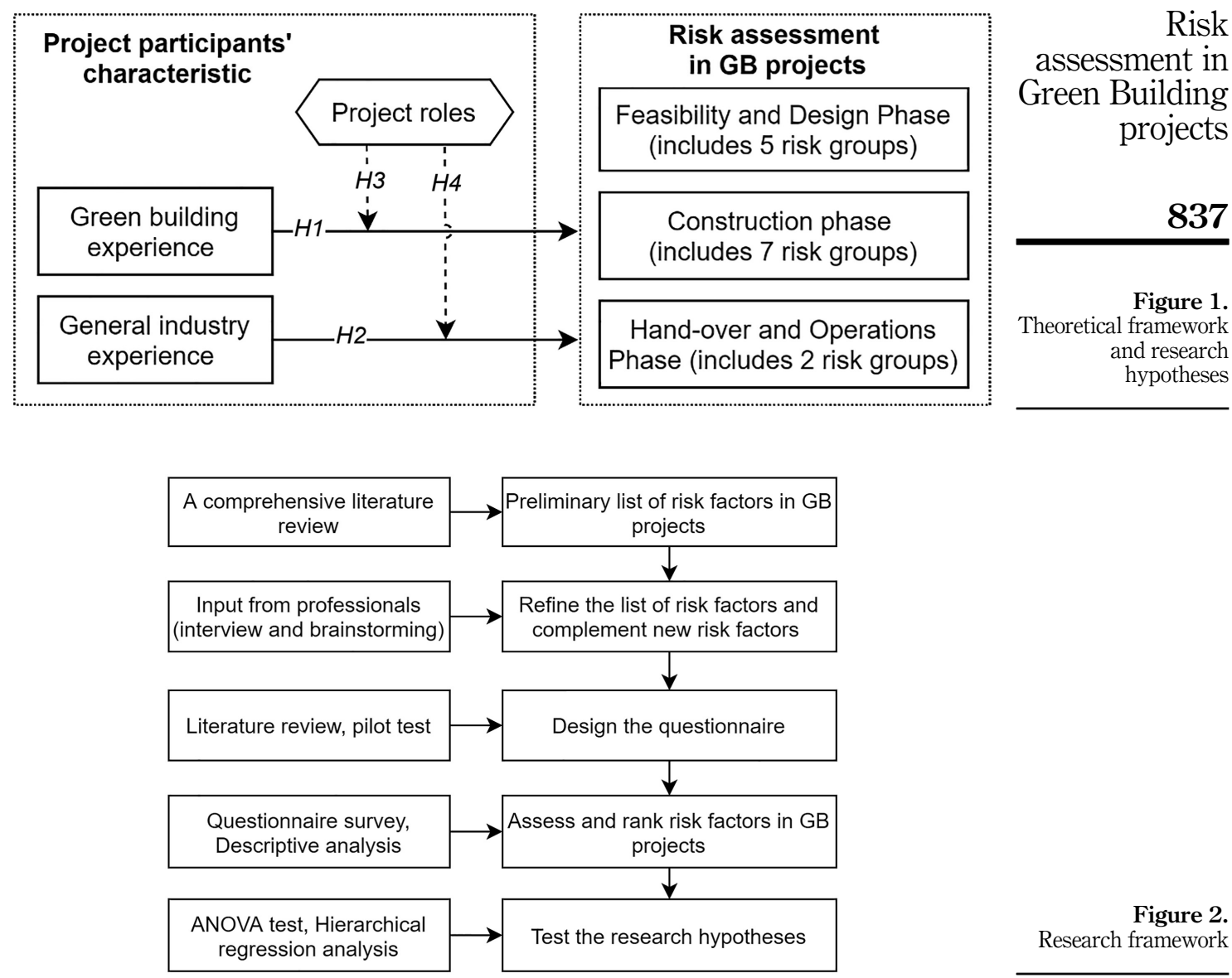

Figure 2. Research framework

\subsection{Identification of risk factors}

A preliminary list of 90 risk factors was identified based on a comprehensive literature review and then classified according to three phases of GB projects (including design, construction and operation phase) based on their features. This list was then analyzed and refined by ten experienced experts through semi-structured interviews and brainstorming (Table 1). The experts have had at least 15 years of construction experience, five years in GB projects and been familiar with RM. The professionals were requested to select risk factors that significantly impact GB projects and review the proposed risk classification based on their experience. In this process, the experts chose many risk factors and also removed unimportant factors. However, many risks were selected by several experts, but not all of the experts. Thus, the authors organized a meeting for the professionals to discuss these debated risks. In the end, the experts collectively selected 48 risk factors that significantly influence the implementation of GB projects.

Additionally, the experts proposed to add five risk factors that can be considered typical risks in Vietnam - a developing country. These risk factors are "late involvement of GB consultant"; "owner lacks determination"; "no general standard for testing the quality and 


\begin{tabular}{|c|c|c|c|c|}
\hline \multirow{2}{*}{$\begin{array}{l}\text { ECAM } \\
30,2\end{array}$} & \\
\hline & Interviewee & Position & Project role & Experience (years) \\
\hline \multirow{7}{*}{838} & $\mathrm{P} 1$ & Senior executive & Owner representative & 29 \\
\hline & P2 & Senior engineer & Designer & 15 \\
\hline & P3 & Division head & Contractor & 27 \\
\hline & P4 & Division head & Designer & 18 \\
\hline & P5 & Division head & Owner representative & 19 \\
\hline & P6 & Division head & Owner representative & 15 \\
\hline & P7 & Division head & Contractor & 21 \\
\hline \multirow{3}{*}{$\begin{array}{l}\text { Table 1. } \\
\text { Experts' profile in the } \\
\text { interviews }\end{array}$} & P8 & Senior engineer & Contractor & 27 \\
\hline & P9 & Senior engineer & Owner representative & 26 \\
\hline & P10 & Senior engineer & Owner representative & 16 \\
\hline
\end{tabular}

origin of green material"; "unrealistic requirements" and "lack of reliable simulation tool." Finally, the list comprises 53 risk factors classified into three phases of GB projects: design, construction and operation (Table 3). Furthermore, the authors and experts attempted to group the risk factors based on their features in each phase. The risk groups used in this classification were referred from previous studies (Zhao et al., 2016; Hwang et al., 2017b; Ismael and Shealy, 2018; Qin et al., 2016) and refined based on discussions with the experts.

\subsection{Design of the survey}

A questionnaire divided into three parts was created to explore the current situation of GB risks in Vietnam. In the first part, we determined the experience and knowledge of respondents about GBs and RM, such as the number of participated GB projects, GB experience and risk knowledge. The second part involved evaluating risk factors through three phases of GB projects. This part also introduced the scale for assessing risk factors with a clear description to facilitate participants' assessment. The final section investigated respondents' background information, such as project role, industry experience and company scope.

The professionals were asked to assess the influence of risk factors on the implementing GB projects by using an ordinal scale $(0=\mathrm{NA} ; 1=$ very low influence; $2=$ low influence; $3=$ moderate influence; $4=$ high influence and $5=$ very high influence). Respondents who did not know the influence of some risk factors could select NA (Croasmun and Ostrom, 2011). The NA would be treated as missing values and omitted from the analysis. Respondents were also encouraged to propose other risk factors missing from the list and suggest possible influences based on their experience. Before conducting the mass survey, 15 professionals were invited to review the appropriateness and clarity of the questionnaire. The pilot test would be completed once most participant experts are consensual about the questionnaire structure. The pilot test ended with trivial changes to the questionnaire.

\subsection{Targeted respondents}

A total of 625 potential respondents, who have experienced GB projects, were identified for the survey. These respondents were identified from the Vietnam Green Building Council (VGBC) and their members. Additionally, based on the recommendations of GB experts, the authors determined consultant companies and contractors who participated in GB projects in Vietnam. The questionnaires were either emailed or hand-delivered to the participants. The interview survey was only used as the respondents were too busy and preferred to answer by meeting face-to-face. Also, we surveyed at two prestigious conferences about GBs by handdelivered the questionnaires to ensure that a group of experienced practitioners would respond. These conferences were organized in Ho Chi Minh City by Green Architecture Club and bring together many leading experts on GBs in Vietnam. Participation in the survey was 
voluntary. Finally, 474 respondents got the questionnaire by email, and 151 received hard copies.

The potential respondents were reminded each month from the first contact to increase the chance of responding. After three months, 219 responses (156 emails and 63 hard copies) were received, resulting in an overall response rate of $35.04 \%$. This response rate is in line with the average $30 \%$ of questionnaire surveys in most previous construction management studies (Akintoye, 2000). Among these, the 12 incomplete responses, which have some unanswered questions, were also removed. Finally, 207 valid responses remained for further analyses.

\subsection{Data analysis}

The survey covered various construction organizations and most relevant stakeholders, such as project management consultants, GB consultants, architects and contractors. The respondents were then classified into three main groups: owner representatives (owners, project management consultant, GB consultant), designers (architect, design engineer) and contractors/subcontractors. As shown in Table 2, 114 respondents (55.07\%) were from owner representatives; 48 respondents $(23.19 \%)$ were architects or design engineering, and 40 respondents $(19.32 \%)$ were contractors or subcontractors. Additionally, Table 2 shows that nearly three-four $(74.88 \%)$ of the participants worked at the managerial or directorial levels, and around $60 \%(58.45 \%)$ had over ten years of experience. The high positions and rich experience of the respondents signified the validity and reliability of the collected data. In terms of GB familiarity, $80.67 \%$ of the respondents participated in GB projects more than "rarely." Furthermore, $61.35 \%$ of participants were "familiar" or "expert" with risk management. These findings once again proved that the responses are reliable for further analysis.

Cronbach's alpha was adopted to test the reliability of the data. The result of Cronbach's alpha was 0.956 for the 53 risk factors, which indicates that the collected data is reliable and suitable for further analysis (Nunnally, 1994).

Several statistical analysis techniques were applied to explore the data. In the first step, descriptive statistics were used to determine mean values, standard deviations and ranking

\begin{tabular}{|c|c|c|c|}
\hline Demographic characteristics & & Frequency & Percent $(\%)$ \\
\hline \multirow[t]{4}{*}{ Project roles } & Owners representatives & 114 & 55.07 \\
\hline & Designers & 48 & 23.19 \\
\hline & Contractors & 40 & 19.32 \\
\hline & Other & 5 & 2.42 \\
\hline \multirow[t]{4}{*}{ Position in organization } & Directorial level & 66 & 31.88 \\
\hline & Managerial level & 89 & 43.00 \\
\hline & Expert level & 43 & 20.77 \\
\hline & Other & 9 & 4.35 \\
\hline \multirow[t]{4}{*}{ Year of experience } & Less than 5 years & 52 & 25.12 \\
\hline & $6-10$ years & 34 & 16.43 \\
\hline & $11-15$ years & 50 & 24.15 \\
\hline & More than 15 years & 71 & 34.30 \\
\hline \multirow[t]{3}{*}{ GB experience } & Often & 63 & 30.43 \\
\hline & Occasionally & 104 & 50.24 \\
\hline & Rarely & 40 & 19.33 \\
\hline \multirow[t]{4}{*}{ Risk knowledge } & Expert & 31 & 14.98 \\
\hline & Familiar & 96 & 46.37 \\
\hline & Somewhat familiar & 62 & 29.95 \\
\hline & Not familiar & $\begin{array}{c}18 \\
(n=207)\end{array}$ & 8.70 \\
\hline
\end{tabular}

Table 2.

The demographic background of the participants 
ECAM

30,2

\begin{tabular}{|c|c|c|c|c|c|}
\hline Code & Risk factors & Mean & $\mathrm{SD}$ & Rank & References \\
\hline $\mathrm{D}$ & Feasibility and design phase & & & & \\
\hline D.Law & Law and policies risk & & & & \\
\hline D1 & $\begin{array}{l}\text { Change in local regulations/governmental policies that } \\
\text { affect the implementation of GB projects }\end{array}$ & 3.70 & 1.23 & 32 & $\begin{array}{l}{[3,4,6,7,9,} \\
11]\end{array}$ \\
\hline D2 & Bureaucracy of authorities & 3.41 & 1.14 & 48 & {$[2,8,11]$} \\
\hline D3 & Complex planning approval and permit procedures & 3.73 & 1.17 & 30 & {$[1,7]$} \\
\hline $\mathrm{D} 4$ & $\begin{array}{l}\text { The regulations on duties, powers and dispute } \\
\text { resolution in GB projects design contracts are unclear }\end{array}$ & 3.68 & 1.02 & 34 & {$[1,2,9,10]$} \\
\hline D.Fin & Financial-Cost risk & & & & \\
\hline D5 & Price inflation of construction materials and labor & 3.65 & 1.02 & 36 & {$[1-3,5,7-11]$} \\
\hline D6 & $\begin{array}{l}\text { Lack of accurate estimation of investment and long-term } \\
\text { return in GB projects }\end{array}$ & 4.12 & 0.84 & 3 & {$[7,8,10,12]$} \\
\hline D7 & $\begin{array}{l}\text { The payback period may be longer than conventional } \\
\text { projects }\end{array}$ & 3.63 & 1.01 & 37 & {$[4,5,17]$} \\
\hline D8 & Underestimation of initial investment cost & 3.98 & 0.89 & 12 & {$[2,4,7]$} \\
\hline D9 & $\begin{array}{l}\text { Fluctuation in exchange rates due to the import of green } \\
\text { materials }\end{array}$ & 3.19 & 1.04 & 53 & $\begin{array}{l}{[1-3,7,10,} \\
11]\end{array}$ \\
\hline D.Man & Management risk & & & & \\
\hline D10 & Delay in decision-making & 3.77 & 0.89 & 27 & [1] \\
\hline D11 & Unrealistic green objectives of GB projects & 3.68 & 0.95 & 35 & {$[2,3$} \\
\hline D12 & $\begin{array}{l}\text { Unclear responsibility of stakeholders in achieving } \\
\text { green certification }\end{array}$ & 3.82 & 0.92 & 23 & [8] \\
\hline D13 & Late involvement of GB consultants in the design phase & 4.26 & 0.81 & 2 & Expert \\
\hline D14 & $\begin{array}{l}\text { Delay caused by frequent meetings with green } \\
\text { consultants }\end{array}$ & 3.48 & 1.00 & 43 & {$[3,11]$} \\
\hline D.Human & Human resource risk & & & & \\
\hline D15 & Project team lack experience in GB design management & 4.06 & 0.84 & 7 & {$[1,6,11]$} \\
\hline D16 & $\begin{array}{l}\text { Inefficient communication and coordination among } \\
\text { stakeholders, especially between GB consultants and } \\
\text { other parties }\end{array}$ & 4.11 & 0.82 & 4 & {$[1,2,5,7]$} \\
\hline D17 & Lack of experienced GB designers & 4.11 & 0.81 & 5 & {$[4-9,11]$} \\
\hline D18 & $\begin{array}{l}\text { Owners lack determination as implementing GB } \\
\text { projects }\end{array}$ & 4.43 & 0.71 & 1 & Expert \\
\hline D.Tech & Technical/Quality risk & & & & \\
\hline D19 & Unclear green requirements of owners & 3.99 & 0.86 & 10 & $\begin{array}{l}{[1-3,7,10,} \\
11]\end{array}$ \\
\hline $\mathrm{D} 20$ & $\begin{array}{l}\text { Insufficient construction site investigation leads to } \\
\text { green design not tailored to local conditions }\end{array}$ & 3.82 & 0.95 & 23 & {$[7,8]$} \\
\hline $\mathrm{D} 21$ & $\begin{array}{l}\text { Inappropriate interventions from owners in adopting } \\
\text { green ideas }\end{array}$ & 3.92 & 0.88 & 15 & {$[1-3,11]$} \\
\hline D22 & $\begin{array}{l}\text { Lack of reliable simulation tools to support the decision- } \\
\text { making in GB projects }\end{array}$ & 3.86 & 0.97 & 18 & Expert \\
\hline D23 & $\begin{array}{l}\text { Unpractical green design ideas due to excessive } \\
\text { creativity compared to conventional design }\end{array}$ & 3.59 & 1.04 & 39 & Expert \\
\hline $\begin{array}{l}\mathrm{C} \\
\text { C.Legal }\end{array}$ & $\begin{array}{l}\text { Construction phase } \\
\text { Legal risk }\end{array}$ & & & & \\
\hline $\mathrm{C} 1$ & $\begin{array}{l}\text { Conditions for resolving disputes, claims and litigation } \\
\text { in GB construction contracts are unclear }\end{array}$ & 3.45 & 1.06 & 46 & {$[1-3,9]$} \\
\hline $\mathrm{C} 2$ & $\begin{array}{l}\text { Difficulty in comprehending green specifications in } \\
\text { contract details }\end{array}$ & 3.50 & 0.96 & 41 & {$[3]$} \\
\hline $\mathrm{C} 3$ & $\begin{array}{l}\text { Delay payments on the contract } \\
\text { Financial/Cost risk }\end{array}$ & 3.45 & 1.10 & 47 & {$[1,5,7]$} \\
\hline $\mathrm{C} 4$ & Labor and materials price fluctuations & 3.35 & 0.98 & 49 & {$[1,10,11]$} \\
\hline
\end{tabular}

The evaluation of $\mathrm{GB}$ risks 


\begin{tabular}{|c|c|c|c|c|c|c|}
\hline Code & Risk factors & Mean & $\mathrm{SD}$ & Rank & References & $\mathrm{K}$ \\
\hline C5 & $\begin{array}{l}\text { Difficulties in project budgeting due to unfamiliarity } \\
\text { with GB projects }\end{array}$ & 3.75 & 0.91 & 29 & {$[3,11]$} & Building \\
\hline $\begin{array}{l}\text { C6 } \\
\text { C.Man }\end{array}$ & $\begin{array}{l}\text { High costs of sustainable materials and equipment } \\
\text { Management risk }\end{array}$ & 3.77 & 0.92 & 26 & {$[3-4,8,11]$} & \\
\hline $\mathrm{C} 7$ & $\begin{array}{l}\text { Poor communication among projects stakeholders in the } \\
\text { construction process of GB projects }\end{array}$ & 3.85 & 0.91 & 19 & {$[1,5,7]$} & 841 \\
\hline $\mathrm{C} 8$ & $\begin{array}{l}\text { Difficulty in the selection of contractors providing GB } \\
\text { construction services }\end{array}$ & 3.61 & 0.95 & 38 & {$[4,6,7,11]$} & \\
\hline C9 & $\begin{array}{l}\text { Slow approval processes due to sustainable } \\
\text { specifications }\end{array}$ & 3.50 & 0.94 & 42 & {$[1,4,7]$} & \\
\hline C.Tech & Technical/Quality risk & & & & & \\
\hline $\mathrm{C} 10$ & $\begin{array}{l}\text { Detail design/green specifications are unclear or } \\
\text { possible errors }\end{array}$ & 3.78 & 0.90 & 25 & {$[1-3,11]$} & \\
\hline $\mathrm{C} 11$ & Design changes during the construction phase & 3.97 & 0.88 & 13 & {$[1,3-5,11]$} & \\
\hline $\mathrm{C} 12$ & Improper quality control process for GB projects & 3.76 & 1.02 & 28 & {$[3,7,10,11]$} & \\
\hline $\mathrm{C} 13$ & $\begin{array}{l}\text { Unfamiliarity with green materials and construction } \\
\text { process }\end{array}$ & 3.57 & 0.94 & 40 & [2] & \\
\hline $\mathrm{C} 14$ & Delay caused by the green construction process & 3.34 & 1.00 & 50 & {$[4,5,8]$} & \\
\hline C.Human & Human resource risk & & & & & \\
\hline $\mathrm{C} 15$ & Unskilled workers about GB construction & 3.26 & 1.12 & 52 & {$[1-8,11]$} & \\
\hline $\mathrm{C} 16$ & $\begin{array}{l}\text { Lack experts have experience and qualified in GB } \\
\text { projects }\end{array}$ & 3.99 & 0.96 & 9 & $\begin{array}{l}{[1-4,7,8,11,} \\
13]\end{array}$ & \\
\hline $\mathrm{C} 17$ & $\begin{array}{l}\text { Lack of experience of contractors/subcontractors in GB } \\
\text { construction }\end{array}$ & 3.69 & 1.05 & 33 & {$[1,2,4-9,11]$} & \\
\hline $\mathrm{C} 18$ & $\begin{array}{l}\text { The project team lacks experience in the construction } \\
\text { management of GB projects }\end{array}$ & 3.95 & 0.91 & 14 & {$[8,9,11]$} & \\
\hline C.Safe & Safety and environmental risk & & & & & \\
\hline $\mathrm{C} 19$ & Construction accidents in GB sites & 3.47 & 1.29 & 45 & {$[1,3,9,10,13]$} & \\
\hline $\mathrm{C} 20$ & Strict safety and health regulations in GB sites & 3.33 & 1.12 & 51 & {$[1,2,6]$} & \\
\hline C21 & High demand for environmental protection in GB sites & 3.48 & 1.09 & 44 & {$[2,6-8]$} & \\
\hline $\mathrm{C} 22$ & Green material quality problems & 3.82 & 0.91 & 23 & {$[1,4,5,9]$} & \\
\hline $\mathrm{C} 23$ & A limited supply of green materials and products & 3.91 & 0.89 & 16 & {$[1-5,7-12]$} & \\
\hline $\mathrm{C} 24$ & $\begin{array}{l}\text { No general standards for testing the quality and origin } \\
\text { of green materials }\end{array}$ & 3.73 & 0.95 & 31 & Expert & \\
\hline $\mathrm{O}$ & Hand-over and operation phase & & & & & \\
\hline O.Man & Management risk & & & & & \\
\hline $\mathrm{O} 1$ & $\begin{array}{l}\text { The project certificate result does not reach the expected } \\
\text { GB standard }\end{array}$ & 4.10 & 0.88 & 6 & {$[4-8,11]$} & \\
\hline $\mathrm{O} 2$ & $\begin{array}{l}\text { The lack of cooperation among the parties involved in } \\
\text { the GB trial operation stage }\end{array}$ & 3.88 & 0.88 & 17 & [8] & \\
\hline $\mathrm{O} 3$ & $\begin{array}{l}\text { Lack of experienced management agency in the } \\
\text { operation phase }\end{array}$ & 3.84 & 0.95 & 20 & {$[7-9]$} & \\
\hline O.Tech & Technical/Quality risk & & & & & \\
\hline & $\begin{array}{l}\text { The performance of green solutions is not achieved as } \\
\text { the original goal }\end{array}$ & 4.03 & 0.92 & 8 & {$[2,5-8,12]$} & \\
\hline $\mathrm{O} 5$ & Lack of adequate GB maintenance & 3.99 & 0.86 & 11 & {$[7,8]$} & \\
\hline $\mathrm{O} 6$ & Difficulties in operating green solutions & 3.84 & 0.90 & 21 & [4], expert & \\
\hline
\end{tabular}

Note(s): [1] Zhao et al. (2016); [2] Hwang et al. (2017a); [3] Hwang et al. (2017b); [4] Ismael and Shealy (2018);

[5] Ranawaka and Mallawaarachchi (2018); [6] Yang et al. (2016); [7] Ahmad et al. (2019); [8] Qin et al. (2016);

[9] Rafindadi et al. (2014); [10] Guan et al. (2020); [11] El-Sayegh et al. (2021); [12] Hwang et al. (2015)

Table 3. 
ECAM

30,2

\section{2}

of risk factors. The descriptive analysis could provide some useful information and also reveal the trend of data. In the second step, some inferential statistics methods, including the ANOVA test and moderated hierarchical regression analysis, were used to test the proposed hypotheses.

Firstly, the ANOVA test was conducted to test $\mathrm{H} 1$ and $\mathrm{H} 2$ (Figure 1). ANOVA test can find out the difference between the levels of each variable. Therefore, ANOVA is suitable for testing the potential relations because each of the hypotheses has one independent variable, including GB experience (GBEx, H1) and industry experience (Ex, H2).

Secondly, hierarchical regression analysis was then performed to test $\mathrm{H} 3$ and $\mathrm{H} 4$ (Figure 1). This method can create several regression models by adding independent variables one by one to preceding regression equations, such as GB experience, project role and the multiplicative interaction (GBEx $\times$ Role). Therefore, the hierarchical regression analysis could help investigate whether the independent variables could explain the statistically significant variance of the dependent variable based on several models (Cohen et al., 2003).

All of the analyses in this research were conducted by Python 3. Packages for the hypotheses test are scipy and statsmodels.

\section{Results}

\subsection{The assessment of $G B$ risk factors}

Firstly, the mean values and standard deviations were calculated to assess the average influence of risk factors in GB projects (Table 3). The mean values range from 3.19 (D9. Fluctuation in exchange rates due to the import of green materials) to 4.42 (D18. Owners lack determination as implementing GB projects). Simultaneously, the standard deviations of risk factors fluctuate around 1 (0.81-1.29). These results indicated considerable differences in the responses regarding the influence of GB risk factors. Furthermore, Table 3 also reveals the rank of risk factors based on their mean values. This may help construction practitioners determine the priority of risks to handle in the RM process.

Additionally, to discover the most significant risks and compare the risk preferences among various roles, Table 4 presents the top ten risks for all roles and each type of role (including the owner, contractor and designer). This information may be helpful in allocating risks among stakeholders in GB projects.

\subsection{Hypotheses test}

4.2.1 Effect of practitioners' GB experience and industry experience on RA (H1 and H2). This step used risk groups to test the research hypotheses because risk factors within a group were mean-centered that could reduce multicollinearity (Aiken et al., 1991). In hypotheses H1 and $\mathrm{H} 2$, this research suggested that participants' GB experience and industry experience are negatively related to RA. To examine these relationships, we first check the box plots created by the Seaborn package in Python3.

Regarding GB experience, the box plot was used to compare RA among GB experience levels (including rarely, occasionally and often) across the risk groups (Figure 3 ). As shown in Figure 3, the level "rarely" had the highest evaluation compared to the two remaining levels ("occasionally" and "often") across most risk groups. Also, this figure shows the tendency that if the participants' GB experience increases, their RA results will decrease. Therefore, this figure seems to support hypothesis $\mathrm{H} 1$ that proposed the negative relationship between GB experience and RA.

In terms of industry experience, Figure 4 compares RA among industry experience levels across risk groups. According to Figure 4, there were no significant differences in RA among industry experience levels across all risk groups. This might imply that $\mathrm{H} 2$ would not be supported. 


\begin{tabular}{|c|c|c|c|c|c|c|c|c|c|}
\hline Rank & $\begin{array}{l}\text { All roles } \\
\text { Code }\end{array}$ & Mean & $\begin{array}{l}\text { Owner } \\
\text { Code }\end{array}$ & Mean & $\begin{array}{l}\text { Contractor } \\
\text { Code }\end{array}$ & Mean & $\begin{array}{l}\text { Designer } \\
\text { Code }\end{array}$ & Mean & $\begin{array}{r}\text { R1sk } \\
\text { assessment in }\end{array}$ \\
\hline 1 & D18 & 4.43 & D18 & 4.34 & D18 & 4.35 & D18 & 4.65 & g \\
\hline 2 & D13 & 4.26 & D13 & 4.25 & D13 & 4.33 & D6 & 4.23 & projects \\
\hline 3 & D6 & 4.12 & D16 & 4.19 & D17 & 4.28 & D17 & 4.21 & \\
\hline 4 & D16 & 4.11 & D15 & 4.12 & D19 & 4.23 & D13 & 4.21 & \\
\hline 5 & D17 & 4.11 & D6 & 4.08 & D6 & 4.15 & $\mathrm{O} 4$ & 4.17 & 843 \\
\hline 6 & $\mathrm{O} 1$ & 4.10 & $\mathrm{O} 1$ & 4.07 & D8 & 4.13 & $\mathrm{O} 1$ & 4.17 & \\
\hline 7 & D15 & 4.06 & D17 & 4.04 & O6 & 4.05 & D22 & 4.13 & \\
\hline 8 & $\mathrm{O} 4$ & 4.03 & $\mathrm{C} 11$ & 4.00 & $\mathrm{O} 1$ & 4.05 & O5 & 4.10 & \\
\hline 9 & $\mathrm{C} 16$ & 3.99 & $\mathrm{O} 4$ & 3.99 & O5 & 4.03 & D8 & 4.10 & \\
\hline 10 & O5 & 3.99 & $\mathrm{C} 16$ & 3.96 & $\mathrm{D} 21$ & 4.03 & $\mathrm{C} 16$ & 4.08 & Top ten risk fa \\
\hline
\end{tabular}

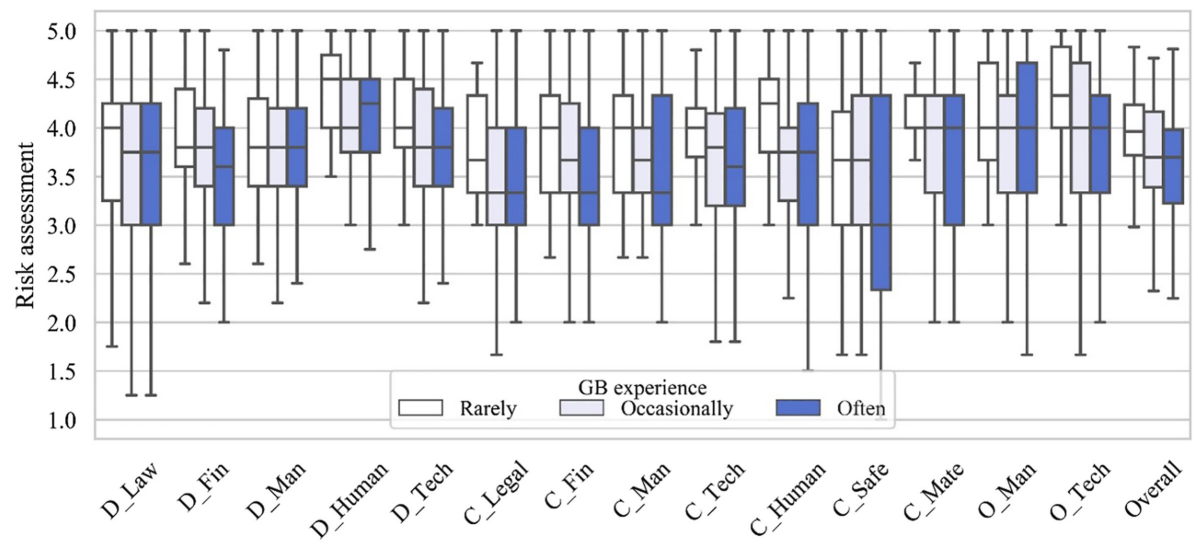

Figure 3.

The effect of participant's GB experience on risk assessment

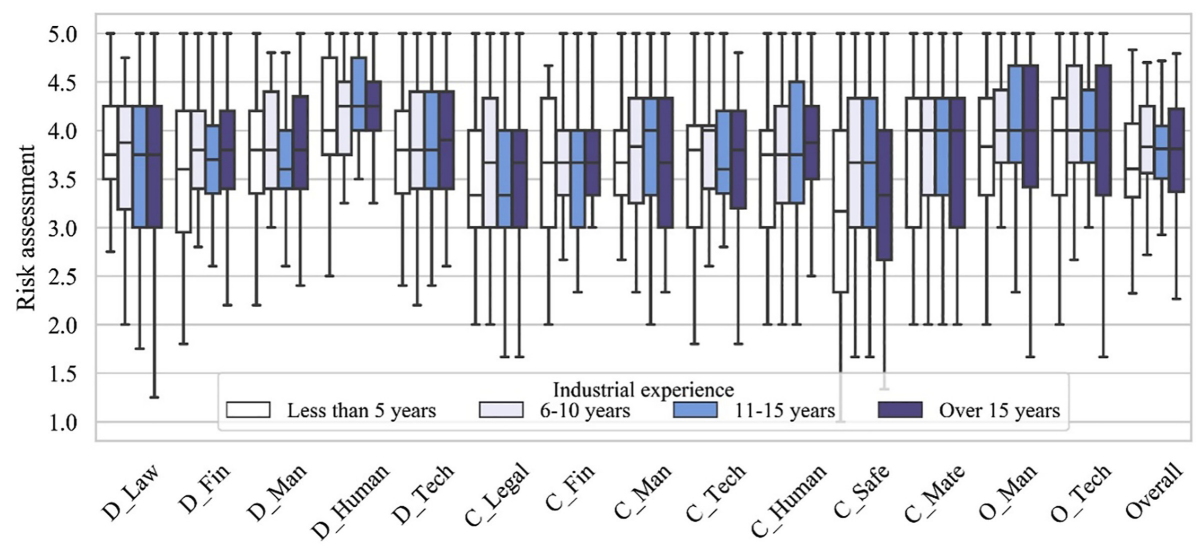

Figure 4. The effect of participant's industry experience on risk assessment 
ECAM

30,2

844

To confirm these speculations, the authors conducted ANOVA to test the relationship between RA and participants' experience, including GB experience and industry experience. Table 5 illustrates the $\mathrm{F}$ statistics and $p$-value of the ANOVA tests for all risk groups and the overall risk.

Table 5 shows that the differences in RA among GB experience levels were statistically significant through most risk groups. There were just three groups (D.Law, D.Man and C.Safe) that were not statistically significant, and the other groups (C.Mate, C.Legal and O.Man) were statistically significant at $p$-values $<0.1$. Furthermore, GB experience was significantly associated with the overall risk $(p$-value $=0.010)$. The result thus supported Hypothesis 1 . Surprisingly, there was no significant correlation between RA and industry experience across all risk groups and overall risk. This could be seen in Table 5 as all $p$-value in the "Industry experience" columns are higher than 0.1. These results thus did not support Hypothesis 2.

4.2.2 Moderating effect of participants' roles (H3). Some previous research debated the impact of project roles on RA in construction projects (Xia et al., 2018). Thus, this might suggest the possible moderating effect of practitioners' roles on the association between GB experience and RA, as proposed in H3. In this section, we did not examine H4 due to $\mathrm{H} 2$ was not supported.

In the first step, the authors used interaction plots to investigate the moderating effect of practitioners' roles on the relation between GB experience and RA. Figure 5 examined overall risk, technical/quality risk (design phase), human resource risk (construction phase) and management risk (operation phase) as representative examples for risk groups. In general, Figure 5 shows the tendency that RA decreases as the GB experience increase. Thus, Figure 5 also confirmed hypothesis H1. Interestingly, contractors had higher assessments compared to owners and designers in the "occasionally" level. However, these differences were not apparent once the participants were in the "rarely" or "often" levels. Thus, we need to conduct statistical tests to conclude $\mathrm{H} 3$.

\begin{tabular}{|c|c|c|c|c|c|}
\hline \multirow[b]{2}{*}{ Code } & \multirow[b]{2}{*}{ Risk groups } & \multicolumn{2}{|c|}{ GB experience (GBEx) } & \multicolumn{2}{|c|}{$\begin{array}{l}\text { Industry experience } \\
\text { (Ex) }\end{array}$} \\
\hline & & $F$ statistic & $P$-value & $F$ statistic & $P$-value \\
\hline \multicolumn{6}{|c|}{ Feasibility and design phase } \\
\hline D.Law & Law and policies & 1.569 & 0.211 & 0.368 & 0.776 \\
\hline D.Fin & Financial/cost & 4.346 & $0.014^{\mathrm{b}}$ & 1.855 & 0.139 \\
\hline D.Man & Management & 1.462 & 0.234 & 1.329 & 0.266 \\
\hline D.Human & Human resource & 4.112 & $0.018^{\mathrm{b}}$ & 0.470 & 0.704 \\
\hline D.Tech & Technical/quality & 4.299 & $0.015^{\mathrm{b}}$ & 0.511 & 0.675 \\
\hline \multicolumn{6}{|c|}{ Construction phase } \\
\hline C.Legal & Legal risk & 2.378 & $0.095^{\mathrm{a}}$ & 0.541 & 0.655 \\
\hline C.Fin & Financial/cost & 6.577 & $0.002^{\mathrm{c}}$ & 1.288 & 0.280 \\
\hline C.Man & Management & 3.221 & $0.042^{\mathrm{b}}$ & 0.824 & 0.482 \\
\hline C.Tech & Technical/quality & 3.830 & $0.023^{\mathrm{b}}$ & 0.987 & 0.400 \\
\hline C.Human & Human resource & 5.880 & $0.003^{\mathrm{c}}$ & 0.677 & 0.567 \\
\hline C.Safe & Safety and environment risks & 1.386 & 0.252 & 1.239 & 0.297 \\
\hline C.Mate & Material and equipment issues & 2.502 & $0.085^{\mathrm{a}}$ & 0.215 & 0.886 \\
\hline \multicolumn{6}{|c|}{ Hand-over and operation phase } \\
\hline O.Man & Management & 2.363 & $0.097^{\mathrm{a}}$ & 1.239 & 0.297 \\
\hline \multirow[t]{2}{*}{ O.Tech } & Technical/quality & 3.523 & $0.031^{\mathrm{b}}$ & 0.886 & 0.449 \\
\hline & Overall & 4.703 & $0.010^{c}$ & 0.858 & 0.464 \\
\hline \multicolumn{6}{|c|}{$\operatorname{Note}(\mathbf{s}):{ }^{\mathrm{a}} p \leq 0.1 ;{ }^{\mathrm{b}} p \leq 0.05,{ }^{\mathrm{c}} p \leq 0.01$} \\
\hline
\end{tabular}

Table 5.
Result of ANOVA for testing hypothesis

Note(s): ${ }^{\mathrm{a}} p \leq 0.1 ;{ }^{\mathrm{b}} p \leq 0.05,{ }^{\mathrm{c}} p \leq 0.01$ 

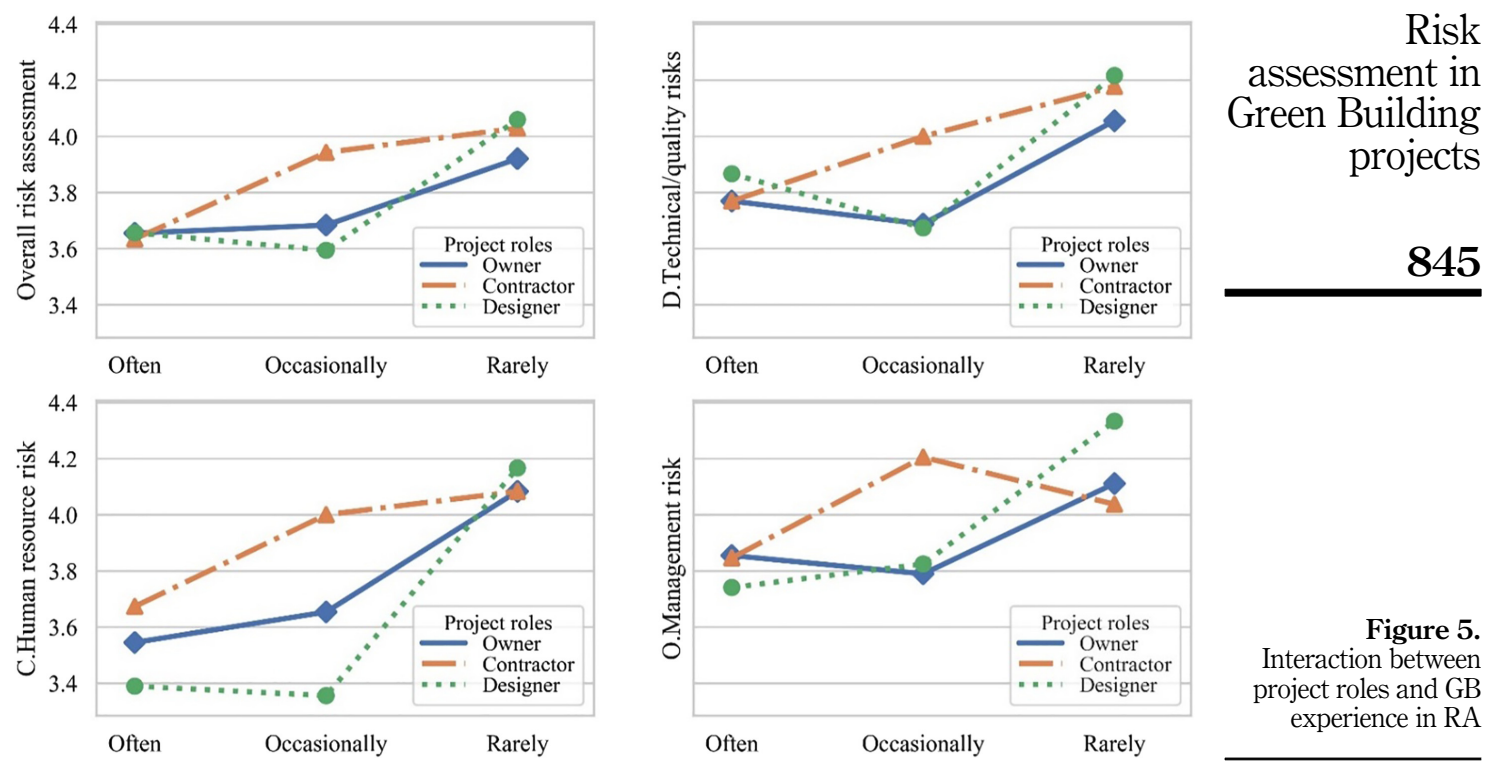

845

The hierarchical multiple regression analysis was performed to further test hypothesis H3. Firstly, two variables were included in Model 1: GB experience (GBEx) and practitioners' role (Role). After that, the authors added the multiplicative interaction variable (GBEx $\times$ Role) in Model 2. In these models, the dependent variable is the overall risk determined by meancentered all risk factors to reduce multicollinearity (Aiken et al., 1991). Table 6 illustrates the main results of hierarchical multiple regression analysis for the overall risk. Also, this research attempted to examine the interactive effect for representative risk groups. The results indicated that they have similar outcomes with the overall risk.

As shown in Table 6, Model 1, which contains two variables: GB experience and practitioners' roles, explained a minor portion of the variance (5.9\%). Nevertheless, Model 1 was still statistically significant with $p$-value $=0.0047(\leq 0.05)$. Notably, the coefficient of Role in Model 1 is insignificant, with $p$-values greater than 0.1 . This implied that project roles do not affect RA in GB projects. Surprisingly, though used interaction variable between GB experience and practitioner role, Model 2 did not explain more significant variance compared

\begin{tabular}{lllcr}
\hline Hypothesis & Study variables & Statistics & Model 1 & Model 2 \\
\hline H3 & GB experience (GBEx).Often & Coefficient & -0.076 & 0.062 \\
& (GBEx).Rarely & Coefficient & $0.260^{\mathrm{b}}$ & $0.466^{\mathrm{b}}$ \\
& Practitioners' role (Role).Designers & Coefficient & 0.161 & $0.349^{\mathrm{b}}$ \\
(Role).Owners & Coefficient & 0.010 & 0.090 \\
Interaction (GBEx.Often $\times$ Role.Designers) & Coefficient & & -0.371 \\
(GBEx. Rarely $\times$ Role.Designers) & Coefficient & & -0.379 \\
(GBEx. Often $\times$ Role.Owners) & Coefficient & & -0.091 \\
(GBEx. Rarely $\times$ Role.Owners) & Coefficient & \multirow{2}{*}{$0.059^{\mathrm{b}}$} & -0.229 \\
& $R^{2}$ & 0.074 \\
& $\Delta R^{2}$ & & 0.015 \\
& & $F$ statistic & $3.018^{\mathrm{b}}$ & 1.928
\end{tabular}

Note(s): ${ }^{\mathrm{a}} p \leq 0.1 ;{ }^{\mathrm{b}} p \leq 0.05 ;{ }^{\mathrm{c}} p \leq 0.01$

Table 6.

Model summary in hierarchical regression analysis 
ECAM

30,2

\section{6}

to Model 1 (only consider GB experience and project role alone). The outcome of a small $\Delta R^{2}$ $(1.5 \%)$ and $p$-value greater than 0.1 proved that project roles do not moderate the association between GB experience and RA. H3 was thus not supported.

Moreover, ANOVA tests were also used to examine the correlation between project roles and RA across all risk groups. The results show that only group "D_Fin" had significant differences in RA among participants' roles (including owners, designers and contractors). This finding is consistent with the hierarchical multiple regression results (Table 6) and in line with previous research (Rafindadi et al., 2014), which claimed no difference in RA among stakeholders in GB projects.

\section{Discussions}

\subsection{Overview of risk assessment results}

In general, the top ten risk factors had mean values above 4.00 (Table 4). This indicated that risks in implementing $\mathrm{GB}$ projects are severe. This finding is consistent with previous studies that claimed GB projects are considerably risky (Hwang et al., 2017b; Zhao et al., 2016).

Regarding all roles, six out of the top ten risk factors occur in the design phase; meanwhile, three factors belonged to the operation phase (Table 4). Notably, only one of the top ten risk factors was in the construction phase. This outcome is unexpected because the construction phase is frequently considered the most uncertain phase in the implementing process of construction projects (Eskander, 2018). Therefore, this indicates that risks in the design and operation phase in GB projects are also critical and have received much attention from stakeholders.

Interestingly, Table 4 also reveals the high consensus among various project roles in identifying the top ten GB risk factors. This may imply that the most critical GB risks could significantly affect multiple stakeholders rather than just a specific party in GB projects. Prominently, the top five risks across each different role (including owners, designers and contractors) belonged to the design phase. Regarding owners' perspectives, six out of the top ten factors are associated with the design phase. The remaining four factors are divided equally for the operation and construction phases. Likewise, for designers, six out of the top ten risk factors are associated with the design phase. Meanwhile, the other four factors relate to the operation phase (3 items) and construction phase $(1$ item). Surprisingly, from the contractor's perspective, seven out of the top ten risks belong to the design phase, and three remaining are related to the operation phase. This indicates $\mathrm{GB}$ risks in the design phase and operation phase also significantly affect contractors. In general, the participants even have a high consensus on top risks. This phenomenon might imply that stakeholders understand risks throughout all phases in GB projects though they work in different roles in GB projects.

\subsection{Discussion of most critical risk factors}

This section presents discussions about the most critical GB risk factors (Table 4). This may help practitioners gain more insight into GB risks and develop measures to mitigate risks in GB projects.

The most critical factor was D18, "Owners lack determination as implementing GB projects." Notably, this is the factor that experts recommended in the brainstorming process (Interviewees P1, P2 and P7); thus, this can be considered a distinct risk of Vietnam compared to developed countries. The high ranking of this factor implies the crucial role of owner determination for GB projects' success. According to the experts (P1 and P2), a common problem in implementing GB projects in Vietnam is that owners tend to give up once they face significant obstacles. Indeed, this problem not only affects the success of GB projects dramatically but also restrains GB development. As suggested by interviewee P2, complementing knowledge and awareness for owners may be helpful to mitigate this risk. 
In the second position, the risk factor D13, "Late involvement of GB consultants in the design phase," had a mean value of 4.26. This is another distinct risk in Vietnam compared to developed countries that experts proposed in the brainstorming process (P3 and P5). This risk factor reflex that owners frequently allow GB consultants to participate in the design process somewhat late in GB projects in Vietnam, as claimed by interviewee P5. Consequently, GB consultants could not contribute to crucial decisions at the beginning of projects. This could dramatically affect GB projects because making changes in later steps is complicated and costly (P3 and P5). To mitigate this risk in the Vietnamese context, provide training courses for owners and project management consultants may be a suitable solution (P1 and P3). The purpose is to help them understand the critical role of GB consultants in GB projects.

The risk factor D6, "Lack of accurate estimation of investment and long-term return in GB projects," occupied the third position. This risk implied that practitioners frequently do not sufficiently estimate the actual profit of GB projects, especially the long-term profit (P1 and $\mathrm{P} 8$ ). As a consequence, owners and other stakeholders may lose motivation to implement GB projects. Thus, this problem could significantly affect owners' determination, as mentioned in the risk factor D18. This factor was also highly evaluated in previous research (Hwang et al., 2015; Qin $e t$ al., 2016). To address this problem, we need to provide practitioners instruction documents to estimate costs and benefits of GB projects based on studies about previous GB buildings' historical data (P1 and P2). Furthermore, such studies also prove the benefits of GBs and thus could increase practitioners' awareness about GBs.

In the following positions, the risk factors D16, D17 and D15 associate with human resources risk in the design phase.

The factor D16 (Inefficient communication and coordination among stakeholders, especially between GB consultants and other parties) implied that collaboration among stakeholders is crucial to GB project success. In reality, the lack of communication among stakeholders is a common issue in the construction industry (Tran and Molenaar, 2014). This is a big problem for any construction project, especially for large and complicated projects. Therefore, for GB projects, which are recognized as complex construction projects, collaboration is even more critical than conventional projects (P4, P6 and P9). Especially, GB consultants' coordinator role is essential in GB projects, as stated in previous studies (Hwang et al., 2017a; Zhao et al., 2016). To handle this risk, the role of project management consultants is crucial, as claimed by interviewee $\mathrm{P} 4$. Therefore, owners should select qualified PM consultants who have experienced GB projects.

The risk factors D17 (Lack of experienced GB designers) and D15 (Project team lack experience in GB design management) reveal the crucial role of qualified professionals in the design phase. The high ranking of these risks indicated that they are still common risk factors of GB projects in Vietnam, as claimed by interviewee P10. These risk factors are also considered many times in the GB literature and have high evaluations in the research of Ismael and Shealy (2018). Admittedly, mitigating these risks is a challenge, especially in a developing country like Vietnam (P1 and P5). In Vietnam's current situation, as the number of GB professionals are limited, providing GB training courses for practitioners is still the most feasible solution (P1, P3 and P5).

Similarly, the risk factor C16 (Lack of experts who have experience and are qualified about GBs) mentions the shortage of skilled professionals in the construction phase. Indeed, GB projects usually adopt innovative technology, novel material and the latest construction procedures that require numerous qualified professionals in the construction process (P2, P3 and P6). Notably, this risk is also mentioned frequently in previous studies (El-Sayegh et al., 2021; Hwang et al., 2017b; Zhao et al., 2016) and was ranked as the second critical risk in the research of Qin et al. (2016). Similar to risks D17 and D15, we can reduce this risk by training construction practitioners. 
ECAM

30,2

\section{8}

Unlike traditional construction projects, the risk factors in the operation phase also play essential roles in GB projects. Thus, it is unsurprising as some risks in the operation phase are present in the top critical risks (Table 4).

In the sixth position, the risk $\mathrm{O1}$, "The project certificate result does not reach the expected GB standard," mentioned GB certification-related problems. Regularly, owners invest in GB projects to get the desired GB certification to benefit their business, as stated by interviewees P1 and P9. Therefore, if the project failed to achieve the expected GB certification, their business will be significantly affected (P1, P4 and P9). Inevitably, other stakeholders also get lost considerably because of this undesirable result. This factor was also mentioned and had a fairly high ranking in previous studies (El-Sayegh et al., 2021; Ismael and Shealy, 2018). To mitigate this risk, the capacity of GB consultants is critical. Thus, owners should choose qualified and prestigious GB consultants to implement GB projects, as suggested by interviewees $\mathrm{P} 1$ and $\mathrm{P} 4$.

In the eighth position, the risk factor $\mathrm{O} 4$ (The performance of green solutions are not achieved as the original goal) is another risk associated with project performance in the operation phase. Indeed, owners expect GBs can benefit their business by saving operating costs (e.g. saving energy and water) and enhancing indoor environments (Guan et al., 2020). Also, the performance goals are always identified and stated at the beginning of GB projects ( $\mathrm{P} 1, \mathrm{P} 2$ and $\mathrm{P} 4)$. Thus, if the project performance is not as predictable, this issue could reduce owners' faith in GBs. The consequence is to restrain the GB development (Nguyen et al, 2017). Unfortunately, this problem is still common in GB projects (Hwang et al., 2017a; Qin et al., 2016). According to experts (P2 and P7), this problem relates to simulation tools predicting GB projects' performance. Thus, develop a reliable simulation tool that can predict the actual performance of GB projects is necessary (P2 and P7). Also, train designers to use simulation tools correctly is essential.

Finally, the risk O5, "Lack of adequate GB maintenance," is another common problem in the operation process. Because GB projects adopt innovative technology and system, maintaining such systems throughout GB life is challenging (P8 and P9). That is why GB certificates are only valid for a specific period (P1 and P8) since GB performance could decrease over time (Guan et al.,2020). Also, this finding was consistent with previous research as lack of adequate maintenance was evaluated as one of GB projects' top five risks in China (Qin et al., 2016). To mitigate this risk, GB consultants need to develop detailed instructions for maintaining systems and equipment in the operating process of GBs, as supposed by interviewees P1 and P8. Also, selecting competent and experienced operators is essential to maximize the efficiency of GBs.

\subsection{The effect of practitioners' characteristics on risk assessment}

This research examined the relationship between practitioner experience (including GB experience and industry experience) and RA. As hypothesized in H1, the ANOVA result verified the negative association between practitioners' GB experience and RA (Table 5). However, surprisingly, Table 5 shows no significant relation between industry experience and RA. These results signify that industry experience might be unhelpful to evaluate GB risks while GB experience plays a crucial role in the RA process. This finding somewhat contrasts with previous research in construction literature, which stated that construction practitioners frequently manage risk based on their industry experience (Taroun, 2014). One plausible interpretation for this phenomenon is that GBs is still a relatively new concept in the construction industry in Vietnam (Nguyen et al., 2017), and GB risks are almost different from risks in traditional projects (Hwang et al., 2017b). Therefore, industry experience alone is not enough to properly assess GB risks, and practitioners need GB experience to manage risks in GB projects. This interpretation explained this phenomenon without rejecting the previous 
research findings in construction literature. Furthermore, this provided new viewpoints about risks in GB projects.

Furthermore, this research investigated the impact of practitioners' roles on RA in GB projects, which is still debated in GB literature. Figure 5 shows that owners and designers do not have significant differences in RA, while contractors' evaluations differ slightly from owners and designers. This might imply that owners and designers have the same point of view about $\mathrm{GB}$ risks. This can be understandable since owners and designers regularly have a bonding relationship in construction projects, especially in the design phase (Nguyen et al., 2021). To consolidate this speculation, the authors carried out the ANOVA test to investigate the association between project roles and RA. However, the results indicated no significant differences in risk preferences among various project roles. This result is consistent with Section 5.1, showing the high consensus among different roles in assessing and ranking top risks. This meant that though there were seemingly differences in RA among various project roles, especially as practitioners occasionally participated in GB projects (Figure 5), these differences were not statistically significant. This finding is also in line with Rafindadi (2014) but conflicts with Qin et al. (2016), who stated differences in RA among various GB project roles. One plausible explanation for this conflict is that GB risk preference among different roles may depend on the specific country contexts. Another reasonable interpretation is that practitioners commonly participate in various GB projects with different roles (interviewees P7, P8 and P10). Thus, they might obtain the viewpoints and experiences of diverse roles in GB projects. Furthermore, most GB projects in Vietnam adopt the design-build project delivery method, as mentioned by interviewee P1. In this approach, stakeholders regularly collaborate stronger and sooner than the traditional project delivery method (e.g. design-bidbuild method) (Tran and Molenaar, 2014). Therefore, they can gain a multidimensional view of risks throughout the life cycle of GB projects. Consequently, the assessments on risks of GB practitioners might be more reliable and converging.

Finally, this research examined the moderating effect of project roles on the association between GB experience and RA. Figure 5 shows that the evaluations of owners, contractors and designers were not much different once they "rarely" participated in GB projects. However, once the practitioners joined GB projects more frequently (to "occasionally" level), their risk assessment decreased, but their differences increased. Nevertheless, these differences disappeared as their GB experience grows to "often." This might hint that practitioners' assessments will be more accurate and converging once they have enough knowledge about GB projects, regardless of their roles. Furthermore, as shown in Figure 5, the shape and tendency of the lines among various roles are just slightly different in all four representative cases. This signified no apparent moderating effect of project roles on the association between GB experience and RA. This speculation was also validated by the hierarchical regression analysis results in Table 6 . This indicated that the negative relationship between $\mathrm{GB}$ experience and RA is still valid once considering each specific project role.

\section{Conclusion}

Improving the prevalence of GBs is necessary to decrease the adverse impact on the environment due to construction industries' activities. Nevertheless, construction practitioners often confront many risks in implementing GB projects. In the current literature, there are limited studies about risks in the implementation process of GB projects, especially in emerging economies. Hence, this study attempted to identify and evaluate risks in the life cycle of GB projects based on data collected in Vietnam. Furthermore, this study investigated the relationship between RA and practitioners' experience. Besides, the moderating effect of practitioners' roles on this relationship was also examined. 
ECAM

30,2

850

As the first contribution, this research revealed mean values, standard deviations and the ranking of risk factors throughout a GB project life cycle. This result can help industry practitioners in the risk management process in GB projects. Notably, the outcome verified the negative association between RA and practitioners' GB experience. In contrast, there was no relationship between industry experience and RA. These findings highlighted the crucial role of qualified professionals with rich GB experience in the RM process in GB projects, especially in a developing country like Vietnam. Unfortunately, the number of GB experts is still very limited in the current situation. One plausible solution is to provide RM training programs based on practical research to construction practitioners. Also, this study exposed slight differences in RA among owners, contractors and designers. However, those differences were not statistically significant and reduced as their GB experience improves. This indicates that stakeholders share and understand most of the risks in GB projects.

Though some previous studies attempted to examine risks in GB projects, there is still a lack of studies investigating GB risks in developing countries. To the best of our knowledge, very few researchers have examined GB risks in developing countries and contributed empirical proof on the influence of practitioners' characteristics on GB risk assessment. Therefore, this research proposed meaningful theoretical contributions to GB literature. Also, this study can be a valuable reference for future researchers interested in pursuing research about GB risks. Regarding the practical aspect, this research could help construction practitioners understand GB risks adequately and have a better risk- management strategy for future GB projects.

Although this study advances knowledge about risks in GB projects, there are still several limitations. The first limitation is that this research focuses on Vietnam's construction industry - a specific developing country. However, the results and implications could be generalized to other developing countries. Regarding the second limitation, this research has to rely on the participants' perceptions of GB risks. Hence, the subjectivity of data is inevitable as participants assess risks based on their experience and knowledge. However, this is a common problem in many studies using questionnaire surveys. Besides, this study has not provided in-depth measures to mitigate risks in GB projects. Case studies or qualitative research (e.g. interviews experts deeply) may address this limitation in future work. Another potential direction is to collect cross-country data to compare GB risks among countries, especially between developed and developing countries. Also, further research should focus on more specific risk cases and consider other characteristics of practitioners.

\section{References}

Ahmad, T., Aibinu, A.A. and Stephan, A. (2019), "Managing green building development - a review of current state of research and future directions", Building and Environment, Elsevier, Vol. 155, pp. 83-104.

Aiken, L.S., West, S.G. and Reno, R.R. (1991), Multiple Regression: Testing and Interpreting Interactions, Sage, Thousand Oaks, CA.

Akintoye, A. (2000), "Analysis of factors influencing project cost estimating practice", Construction Management and Economics, Taylor \& Francis, Vol. 18 No. 1, pp. 77-89.

Alhumaidi, H.M. (2014), "Construction contractors ranking method using multiple decision-makers and multiattribute fuzzy weighted average", Journal of Construction Engineering and Management, American Society of Civil Engineers, Vol. 141 No. 4, p. 4014092.

Analytics, D.D. (2018), "World Green Building Trends 2018 - smart market report, smart market report”, U.S. Green Building Council, available at: www.construction.com.

Chapman, C. and Ward, S. (2004), "Why risk efficiency is a key aspect of best practice projects", International Journal of Project Management, Elsevier, Vol. 22 No. 8, pp. 619-632. 
Cohen, J., Cohen, P., West, S.G. and Aiken, L.S. (2003), Applied Multiple Regression/Correlation Analysis for the Behavioral Sciences, 3rd ed., Lawrence Erlbaum, Mahwah, NJ.

Croasmun, J.T. and Ostrom, L. (2011), "Using Likert-type scales in the social sciences", Journal of Adult Education, ERIC, Vol. 40 No. 1, pp. 19-22.

Du, L., Tang, W., Liu, C., Wang, S., Wang, T., Shen, W., Huang, M. and Zhou, Y. (2016), "Enhancing engineer-procure-construct project performance by partnering in international markets: perspective from Chinese construction companies", International Journal of Project Management, Elsevier, Vol. 34 No.1, pp. 30-43.

Risk

assessment in Green Building projects

El-Sayegh, S.M., Manjikian, S., Ibrahim, A., Abouelyousr, A. and Jabbour, R. (2021), "Risk identification and assessment in sustainable construction projects in the UAE", International Journal of Construction Management, Vol. 21 No. 4, pp. 327-336, doi: 10.1080/15623599.2018. 1536963.

Eskander, R.F.A. (2018), "Risk assessment influencing factors for Arabian construction projects using analytic hierarchy process", Alexandria Engineering Journal, Elsevier, Vol. 57 No. 4, pp. 4207-4218.

Gan, X., Zuo, J., Ye, K., Skitmore, M. and Xiong, B. (2015), "Why sustainable construction? Why not? An owner's perspective”, Habitat International, Elsevier, Vol. 47, pp. 61-68.

Guan, L., Abbasi, A. and Ryan, M.J. (2020), "Analyzing green building project risk interdependencies using Interpretive Structural Modeling", Journal of Cleaner Production, Elsevier, Vol. 256, p. 120372.

Hwang, B.-G., Zhao, X., See, Y.L. and Zhong, Y. (2015), “Addressing risks in green retrofit projects: the case of Singapore", Project Management Journal, Wiley Online Library, Vol. 46 No. 4, pp. 76-89.

Hwang, B.-G., Shan, M., Phua, H. and Chi, S. (2017a), "An exploratory analysis of risks in green residential building construction projects: the case of Singapore", Sustainability, Multidisciplinary Digital Publishing Institute, Vol. 9 No. 7, p. 1116.

Hwang, B., Shan, M., Supa'at, N.N.B. and Supa'at, N.N.B. (2017b), "Green commercial building projects in Singapore: critical risk factors and mitigation measures", Sustainable Cities and Society, Elsevier, Vol. 30, pp. 237-247.

Islam, M.S., Nepal, M.P., Skitmore, M. and Attarzadeh, M. (2017), "Current research trends and application areas of fuzzy and hybrid methods to the risk assessment of construction projects", Advanced Engineering Informatics, Elsevier, Vol. 33, pp. 112-131.

Ismael, D. and Shealy, T. (2018), "Sustainable construction risk perceptions in the Kuwaiti construction industry”, Sustainability, Multidisciplinary Digital Publishing Institute, Vol. 10 No. 6, p. 1854.

Kientzel, J. and Kok, G. (2011), "Environmental assessment methodologies for commercial buildings: an elicitation study of U.S. Building professionals' beliefs on leadership in energy and environmental design (LEED)", Sustainability, Molecular Diversity Preservation International, Vol. 3 No. 12, pp. 2392-2412.

Latham, M. (1994), Constructing the Team: Final Report of the Government/Industry Review of Procurement and Contractual Arrangements in the UK Construction Industry, Hmso, London.

Li, N., Fang, D. and Sun, Y. (2015), "Cognitive psychological approach for risk assessment in construction projects", Journal of Management in Engineering, American Society of Civil Engineers, Vol. 32 No. 2, p. 4015037.

Nguyen, H.-T.T., Skitmore, M., Gray, M., Zhang, X. and Olanipekun, A.O. (2017), "Will green building development take off? An exploratory study of barriers to green building in Vietnam", Resources, Conservation and Recycling, Elsevier, Vol. 127, pp. 8-20.

Nguyen, H.D., Dang, C.N., Le-Hoai, L. and Luu, Q.T. (2021), "Exploratory analysis of legal risk causes in tourism real estate projects in emerging economies: empirical study from Vietnam", International Journal of Construction Management, Taylor \& Francis, pp. 1-13, doi: 10.1080/ 15623599.2021.1937907. 
ECAM

30,2
Nguyen, H.D., Nguyen, L.D., Chih, Y.-Y. and Le-Hoai, L. (2017), "Influence of participants' characteristics on sustainable building practices in emerging economies: empirical case study", Journal of Construction Engineering and Management, American Society of Civil Engineers, Vol. 143 No. 8, p. 05017014.

Nunnally, J.C. (1994), Psychometric Theory 3E, Tata McGraw-Hill Education, New York.

Patterson, F.D. and Neailey, K. (2002), "A risk register database system to aid the management of project risk", International Journal of Project Management, Elsevier, Vol. 20 No. 5, pp. 365-374.

PMI (2017), A Guide to the Project Management Body of Knowledge (PMBOK Guide), 6th ed., Project Management Institute, Newtown Square, PA.

Qin, X., Mo, Y. and Jing, L. (2016), "Risk perceptions of the life-cycle of green buildings in China", Journal of Cleaner Production, Elsevier, Vol. 126, pp. 148-158.

Rafindadi, A.D., Mikić, M., Kovačić, I. and Cekić, Z. (2014), "Global perception of sustainable construction project risks", Procedia-Social and Behavioral Sciences, Elsevier 1995, Vol. 119 No. Williams, pp. 456-465.

Ranawaka, I. and Mallawaarachchi, H. (2018), “A risk-responsive framework for green retrofit projects in Sri Lanka", Built Environment Project and Asset Management, Emerald Publishing, Vol. 8 No. 5, pp. 477-490.

Raz, T. and Michael, E. (2001), "Use and benefits of tools for project risk management", International Journal of Project Management, Elsevier, Vol. 19 No. 1, pp. 9-17.

Retzlaff, R. (2010), "Developing policies for green buildings: what can the United States learn from The Netherlands?”, Sustainability: Science, Practice and Policy, Taylor \& Francis, Vol. 6 No. 1, pp. 28-38.

Tao, X. and Xiang-Yuan, S. (2018), "Identification of risk in green building projects based on the perspective of sustainability", IOP Conference Series: Materials Science and Engineering, Vol. 439, p. 32053.

Taroun, A. (2014), "Towards a better modelling and assessment of construction risk: insights from a literature review", International Journal of Project Management, Elsevier, Vol. 32 No. 1, pp. 101-115.

Tran, D.Q. and Molenaar, K.R. (2014), "Impact of risk on design-build selection for highway design and construction projects", Journal of Management in Engineering, Vol. 30 No. 2, pp. 153-162.

Wood, G.D. and Ellis, R.C.T. (2003), "Risk management practices of leading UK cost consultants", Engineering, Construction and Architectural Management, MCB UP.

Xia, N., Zou, P.X.W.W., Griffin, M.A., Wang, X. and Zhong, R. (2018), "Towards integrating construction risk management and stakeholder management: a systematic literature review and future research agendas", International Journal of Project Management, Elsevier, Vol. 36 No. 5, pp. 701-715.

Yang, R.J., Zou, P.X.W.W. and Wang, J. (2016), "Modelling stakeholder-associated risk networks in green building projects", International Journal of Project Management, Elsevier and Association for Project Management and the International Project Management Association, Vol. 34 No. 1, pp. 66-81.

Zhao, X., Hwang, B.-G.G. and Gao, Y. (2016), "A fuzzy synthetic evaluation approach for risk assessment: a case of Singapore's green projects", Journal of Cleaner Production, Elsevier, Vol. 115, pp. 203-213.

\section{Corresponding author}

Hung Duy Nguyen can be contacted at: duyhung.nguyen@studenti.unipd.it

For instructions on how to order reprints of this article, please visit our website:

www.emeraldgrouppublishing.com/licensing/reprints.htm

Or contact us for further details: permissions@emeraldinsight.com 